\title{
Contribuições da concepção vigotskiana de arte para o ensino da cultura corporal
}

\author{
Telma Adriana Pacifico Martineli \\ Universidade Estadual de Maringá - Maringá - PR - Brasil \\ Eliane Maria Almeida \\ Universidade Estadual de Maringá - Maringá - PR - Brasil
}

\begin{abstract}
Resumo
Este estudo analisa a concepção de arte desenvolvida por L. S. Vigotski (1896-1934) e suas contribuições para o ensino da cultura corporal, na educação física escolar. Especifica-se o contexto de sua produção e divulgação no Brasil, as concepções de arte e infância desse psicólogo, bem como suas possibilidades pedagógicas no ensino da cultura corporal. As principais referências de estudo foram: "A imaginação e a arte na infância" e "Psicologia da arte" de Vigotski (2006, 1999), elaboradas no contexto da Revolução Russa e recuperadas na abertura política e social no Brasil. Para o autor, o homem tem capacidade reprodutora e criativa e a partir dela produz arte. A imaginação é uma função psicológica superior que deve ser potencializada na infância para o desenvolvimento da capacidade criativa e da subjetividade humana. Portanto, a atividade pedagógica no ensino da cultura corporal, fundamentada nessa teoria, pode favorecer o desenvolvimento da capacidade criativa na infância.
\end{abstract}

Palavras-Chave: Educação Física; Vygotsky; Arte.

\section{Contributions of the Vygotskian conception of art for the teaching of body culture}

\begin{abstract}
This study analyzes the art conception developed by L. S. Vigotski (1896-1934) and his contributions to the teaching of body culture in school physical education. It specifies the context of its production and dissemination in Brazil, the conceptions of art and childhood of this psychologist, as well as its pedagogical possibilities in the teaching of body culture. The main references of study were: "The imagination and the art in the childhood" and "Psychology of the art" of Vigotski (2006, 1999), elaborated in the context of the Russian Revolution and recovered in the political and social opening in Brazil. For the author, the human being has reproductive and creative capacity and from it produces art. Imagination is a superior psychological function that must be strengthened in childhood for the development of creative capacity and human subjectivity. Therefore, pedagogical activity in the teaching of body culture, based on this theory, can favor the development of creative capacity in childhood.
\end{abstract}

Keywords: Physical Education; Vygotsky; Art.

\section{Contribuciones de la concepción vigotskiana de arte a la enseñanza de la cultura corporal}

\section{Resumen}

En este estudio se analiza la concepción de arte desarrollada por L. S. Vygotsky (1896-1934) y sus contribuciones a la enseñanza de la cultura corporal, en la educación física escolar. Se especifica el contexto de su producción y divulgación en Brasil, las concepciones de arte e infancia de ese psicólogo, así como sus posibilidades pedagógicas en la enseñanza de la cultura corporal. Las principales referencias de estudio fueron: "La imaginación y el arte en la infancia" y "Psicología del arte" de Vygotsky (2006, 1999), elaboradas en el contexto de la Revolución Rusa y recuperadas en la abertura política y social en Brasil. Para el autor, el hombre tiene capacidad reproductora y creativa y a partir de ella produce arte. La imaginación es una función psicológica superior que debe ser potencializada en la infancia para el desarrollo de la capacidad creativa y de la subjetividad humana. Por lo tanto, la actividad pedagógica en la enseñanza de la cultura corporal, fundamentada en esa teoría, puede favorecer el desarrollo de la capacidad creativa en la infancia.

Palabras clave: Educación Física; Vygotsky; Arte. 


\section{Introdução}

A educação física como atividade social e pedagógica sofreu múltiplas influências na sua constituição histórica, entre elas a da arte, seja ela da arte cênica, da música ou da dança. A ginástica, a dança, a mímica são formas de manifestações artísticas da cultura corporal (Soares \& cols., 1992).

O estudo de Soares (2005) analisou a educação do corpo, a partir do método ginástico francês. A autora utilizou como objetos de análise de livros, especialmente de Demeny e Amoros e de G. Flaubert e E. Zola, de artes plásticas, pinturas, imagens fotográficas, ilustrações de livros e quadros; enfim, produções artísticas elaboradas sobre a ginástica no século XIX, as quais revelavam uma educação do corpo e auxiliavam na compreensão das ações humanas ao longo do tempo. O estudo apresenta imagens de obras históricas de arte como as de Giandomenico Tiepolo (1727-1804) "Polichinelos e Saltimbancos" de 1793; de Pieter Brueguel (1525-1569) "Jogos Infantis" (1560), "A dança dos camponeses" (1568) e "Dança nupcial ao ar livre" (1556); de Francisco de Goya (1746-1828)"O enterro da Sardinha"(1812), "O Boneco de palha (1791-1792) e "Os pequenos gigantes"; de Georges Seurat (1859-1891) "O Circo" (1891), entre outras produções de artistas importantes como Jerôme Bosch (1450-1516), Toulouse-Lautrec (1864-1901) de Edgar Degas (1834-1917), Pierre Auguste Renoir (1841-1919) e Van Gogh (1853-1890). Embora a autora não tenha realizado análise profunda de cada uma das obras utilizadas na pesquisa, ela abordou e contextualizou os objetivos da Escola Francesa de Ginástica e sua influência no desenvolvimento histórico da educação física.

O objeto de estudo de Soares (2005) despertou a atenção de pesquisadores e professores da área educação física para a possibilidade do uso de obras de arte para a compreensão do processo histórico de constituição da cultura corporal. Esse e outros estudos ligados à arte e à cultura contribuíram para buscar a compreensão, em uma perspectiva histórico-cultural, da formação social da dimensão lúdica e artística do ser humano, assim como sua relação com a constituição histórica da educação física e de seu objeto de estudo e de ação pedagógica: a cultura corporal.

As manifestações artísticas da cultura corporal constituem-se em objeto de estudos do Grupo de Pesquisa Educação Física, Arte e Cultura (GEFAC), do Departamento de Educação Física da Universidade Estadual de Maringá (UEM). O referencial teórico-metodológico que fundamenta os estudos é o Materialismo Histórico e a Psicologia Histórico-Cultural. Entre os estudos desenvolvidos pelo grupo, nessa perspectiva, cita-se Piedade (2004), que fez uma análise sobre a construção do corpo expressivo nas obras de Constantin Stanilavski (1863-1938) e Bertold Brecht (1898-1956); Palharini (2007), que estudou as atividades da cultura corporal em crianças; e, por fim, Marroni (2003), que analisou historicamente a atividade circense como manifestação artística e cultural.
Estudos fundamentados na Psicologia histórico-cultural, elaborada por Lev Semenovitch Vigotski (1896-1934), Alexei Nikolaevich Leontiev (1903-1979) e Alexander Romanovich Luria (1902-1977) ganharam notoriedade entre grupos de pesquisadores da psicologia e da educação no Brasil. Isso se explica no entendimento de Barroco e Superti (2014, p. 23) pelo fato de que "sua teoria pautada na constituição social do psiquismo apresentou nova dimensão para a formação e atuação de profissionais vinculados a essas áreas". Todavia, muitas das produções de Vigotski, inclusive as obras relacionadas à arte carecem de estudos, afirmam as autoras.

Essa realidade se expressa também na área da Educação Física, especialmente pela sua relação histórica com a arte e por se constituir num campo profícuo para análise e investigação. Acredita-se que os estudos pautados nessa perspectiva possam contribuir para compreender a formação social da dimensão lúdica e artística do ser humano, sua relação com a produção histórica das manifestações da cultura corporal e da educação física como área e disciplina escolar ${ }^{1}$.

Neste manuscrito, decorrente de estudos da Teoria Histórico-Cultural, propõe-se a analisar a concepção de arte, de Vigotski, particularmente na infância, bem como suas contribuições para a compreensão da cultura corporal e para o ensino da educação física, com vistas ao desenvolvimento da imaginação e da capacidade criativa de crianças. As referências principais deste estudo foram os livros "Psicologia da arte" (Vigotski, 1999) e La imaginación y el arte en la infância (Vigotski, 2006) de Vigotski, dentre outras referências de autores que estudam a arte nessa concepção.

\section{O contexto da produção da obra de Vigotski sobre arte}

Vigotski elaborou as bases fundamentais de sua concepção a respeito da formação social do psiquismo no contexto da Revolução Russa. Shuare (1990, p. 25) explica que:

O processo iniciado na Rússia, em 1917, implicou necessariamente em choques profundos no plano da consciência social; basta citar, para convencer-se dele, os movimentos transformadores na poesia, no teatro, no cinema, na pintura, na linguística, etc., que, vinham se desenhando anos antes, encontraram nesse momento a atmosfera propícia para seu desenvolvimento.

Nesse contexto, Vigotski elaborou sua concepção de arte e refletiu a respeito da relação dessa concepção com o desenvolvimento humano na infância. Esse autor examinou, na década de 1920, um complexo problema: o caráter e o desenvolvimento da imaginação artística na criança. Ele dedicou-se aos estudos da atividade reprodutiva e da atividade

1 A educação física está assegurada como componente da Educação Básica nas escolas brasileiras pela Lei de Diretrizes e Bases da Educação Nacional n. 9394/96 (1996). 
criativa e, fundamentalmente, da relação entre a imaginação e a arte na infância, conteúdo esse materializado no livro intitulado: La imaginación y el arte en la infância, publicado originalmente em 1930. Em seu estudo sobre a psicologia da arte, desenvolvido entre os anos de 1924 e 1926, e publicado no Brasil somente em 1999 em forma de livro, com o título "Psicologia da Arte", Vigotski (1999) estudou questões relativas à metodologia do problema, tece críticas às concepções de arte, faz uma análise minuciosa da reação estética, e, por fim, trata da psicologia da arte.

As críticas sociais, políticas e econômicas que borbulhavam no Mundo Ocidental, por sua vez, influenciaram a sociedade brasileira. Algumas das obras de Vigotski foram inicialmente recuperadas no Brasil, no contexto de profundas mudanças sociais e políticas no país, e do processo de redemocratização no início de 1980, por pesquisadores educacionais brasileiros que buscavam compreender seus pressupostos (Jacomé, 2006). Esse momento político favoreceu a divulgação de novas ideias no país e as concepções de Vigotski e de seus colaboradores atendiam a esse anseio de grupos de estudiosos brasileiros (Jacomé, 2006).

As primeiras produções de Vigotski traduzidas no Brasil foram: "A formação social da mente", em 1994 e "Pensamento e Linguagem", publicada em 1987, ambas advindas de versões norte-americanas, cujos limites das traduções dificultaram, inicialmente, a compreensão do pensamento desse autor. Portanto, é relativamente recente a difusão da teoria vigotskiana e de seus colaboradores em nosso país. Na literatura pesquisada por Silva e Davis, (2004, p. 634) foram encontrados quatro autores brasileiros: "Oliveira (1992), Freitas (1994), Tuleski (2001) e Duarte (2000) que buscaram, com objetivos distintos, organizar as apropriações das ideias de Vigotski".

Sarmento (2006) concluiu, em seu estudo sobre a produção acadêmica e científica da Teoria Histórico-Cultural no período de 1986 a 2001 no Brasil, que quatro (4) universidades podem ser consideradas polos de difusão da abordagem de Vigotski, pois juntas totalizam 64,3\% das teses e dissertações sobre esse referencial: Pontifícia Universidade Católica de São Paulo (PUCSP), a Universidade Federal de Santa Catarina (UFSC), a Universidade Estadual de Campinas (UNICAMP) e a Universidade de São Paulo (USP). Os periódicos que possuem o maior número de artigos que se definem pelo referencial teórico vigotskiano são: Cadernos de Pesquisa da Fundação Carlos Chagas, Educação e Sociedade, Psicologia em Estudo e Psicologia: Teoria e Pesquisa.

No que concerne especificamente, à cultura, à arte e à literatura na concepção vigotskiana, os estudos ganharam impulso a partir da publicação de "Psicologia da Arte" de Vigotski (1999), bem como dos textos escolhidos de Marx e Engels (2010), coletados de suas obras clássicas e da obra de Lukács (1885-1971) e Lifschitz (1915-1985), principais teóricos sobre estética nessa perspectiva teórica. Barroco (2007) é uma das principais pesquisadoras da psicologia e da educação que tem empreendido estudos sobre arte nessa concepção no país.
Na área da educação física, o interesse de grupos de pesquisadores como Soares e cols. (1992), ao buscar subsídios em Vigotski, Leontiev e Davídov, sobre questões pedagógicas e a proposição de ciclos de escolarização, abriu possibilidades para outros estudos e ações nessa perspectiva. Ao atribuir importância aos teóricos da Psicologia Histórico-Cultural e às suas possíveis contribuições, fortaleceram os estudos nessa teoria, ainda que limitados a alguns grupos, dada a proliferação de perspectivas neoconservadoras nesta área.

Um levantamento recente de produções científicas, em seis (6) periódicos indexados nacionais da área da educação física: Revista Movimento, Revista Motriz, Revista Brasileira de Ciências do Esporte, Revista Brasileira de Educação Física e Esporte, Revista da Educação Física/ UEM e Revista Pensar a Prática, cujo intuito foi analisar as produções na especificidade das manifestações gímnicas, permitiu encontrar 132 artigos, dos quais apenas três (3) artigos abordavam a Teoria Histórico-Cultural; todos os trabalhos tratavam do ensino da ginástica no contexto educacional, abordando conceitos relativos à aprendizagem da teoria vigotskiana, porém sem utilizar esse referencial teórico-metodológico para fundamentar seus estudos e análises. Foram encontrados também três (3) artigos que tratavam especificamente das manifestações artísticas, estéticas e expressivas da ginástica, cujas análises realizadas utilizaram fundamentações teórico-metodológicas distintas (fenomenologia, existencialismo), sem nenhuma aproximação com a concepção de arte de Vigotski (Almeida, 2015). Em face desses dados, apresenta-se a seguir a síntese deste estudo sobre arte à luz da Psicologia Histórico-Cultural.

\section{A concepção de arte em Vigotski}

Para este trabalho, foram delimitados os estudos de Vigotski a respeito da arte e seu desenvolvimento na infância. Vale destacar que o estudo das questões da arte e da estética de Vigotski, fundamentado no materialismo histórico, não se desprende da ontologia do ser social, ou seja, das origens do ser social fundado no trabalho.

A vida dos homens, suas relações sociais fundadas no trabalho - como ação do homem sobre a natureza, possibilitou o seu desenvolvimento sócio histórico. Vigotski e Leontiev enfatizam, em seus estudos, a riqueza do homem e da cultura, afirmando que o psiquismo humano carrega e expressa as marcas do tempo em que se vive na história da humanidade, pois o homem é ao mesmo tempo criador e criatura nesse processo. Leontiev (1978) afirma que, ao se apropriar dos instrumentos materiais e sociais, o homem desenvolveu suas faculdades motoras e psíquicas superiores, em decorrência das condições internas e externas e das necessidades sociais. Nessa concepção

Os progressos realizados na produção dos bens materiais são acompanhados pelo desenvolvimento da cultura dos homens; o seu conhecimento do mundo circundante e deles 
mesmos enriquece-se, desenvolvem-se a ciência e a arte. É, aliás, o caso da atividade humana fundamental: o trabalho (Leontiev, 1978, p. 265).

Vigotski (1999) entende que a arte aparece como fenômeno humano, que decorre da relação direta ou mediata do homem como um cosmo físico, social e cultural, onde se constroem e se multiplicam variedades de facetas e nuanças que caracterizam o homem como integrante desse cosmo. Esse autor concebe a arte como o social entre nós.

Graças ao prévio desenvolvimento técnico da arte e das condições culturais nas quais Rafael ${ }^{2}$ estava inserido foi-lhe possível desenvolver todo o seu potencial artístico. Ainda que um sujeito traga dentro de si um Rafael, sem os progressos técnicos alcançados pelas gerações anteriores e sem a organização da sociedade e a divisão do trabalho no lugar onde esse sujeito está situado, não lhe seria possível desenvolver o seu potencial ou sua capacidade artística (Marx, 2010).

Marx (2010) esclarece o quão dialética é a relação entre criação e percepção na produção da arte. À medida que se produz um objeto material para suprir uma necessidade, oferece-se uma necessidade ao objeto material. "O objeto da arte - como qualquer outro produto - cria um público capaz de compreender a arte e de fruir a sua beleza. Portanto, a produção não produz somente um objeto para o sujeito, mas também um sujeito para o objeto" (Marx, 2010, p. 137). Desse modo, o objeto/produto da arte que é criado para o sujeito cria também nesse sujeito a capacidade de compreendê-lo e desfrutar dele, de se deleitar com a sua beleza. Barroco e Superti (2014, p. 22) sintetizam que

...o objeto da psicologia da arte é o estudo da estrutura da obra, que deve provocar uma resposta estética e impactar a psique do fruidor. Considera-se que a arte, por sua estrutura específica e condição de objeto cultural, pode trazer desenvolvimento à psique humana, pois, entre outros aspectos, possibilita a duplicação do real no âmbito intrapsíquico, ao oferecer ao fruidor a vivência, por meio indireto, sobretudo de emoções e sentimentos não cotidianos (Barroco \& Superti, 2014, p.22).

Desse modo, só é possível relacionar-se de maneira humana com uma coisa quando esta se relaciona de maneira humana com o homem, ou seja, um objeto se torna um objeto social, como um ser social, bem como o homem se torna um objeto ao reconhecer nos objetos objetivações de si próprio. Assim, somente pela riqueza objetivamente desenvolvida do ser social é que a riqueza da sensibilidade humana subjetiva é cultivada ou criada e são desenvolvidos os sentidos espirituais ou os sentidos práticos, como as sensibilidades, desejar e amar por exemplo. O olho huma-

2 Rafael Sanzio, referenciado apenas como Rafael, mestre da pintura e da arquitetura da Escola de Florença durante 0 Renascimento italiano, citado por Marx e Engels em seus escritos, quando abordam questões afetas à arte. no aprecia as coisas de maneira diferente do olho bruto, o sentido musical do homem é despertado pela música e não terá sentido nenhum para um ouvido não musical. Portanto, a objetificação da essência humana é necessária para humanizar os homens e criar os sentidos humanos correspondentes a toda a riqueza cultural do ser humano (Marx \& Engels, 2010).

Em síntese, a capacidade criativa e de produção da arte se desenvolveu na ontogênese do ser social, a partir do enriquecimento do mundo circundante dos homens e da apropriação de seus bens culturais. No processo ontológico, edificaram-se as condições necessárias para que o homem, por meio de seus gestos e, posteriormente, por atividades corporais tecnicamente mais complexas, pudesse produzir arte, tal como a mímica, a dança, a ginástica, ou seja, as mais variadas formas de expressão corporal produzidas pelo homem ao longo da história. A educação física tem uma íntima relação com a arte, pois suas formas de expressão são fruto da produção criativa do homem, que se transformam em produto cultural, em particular, em cultura corporal.

\section{Imaginação, arte e infância na teoria de Vigotski}

\begin{abstract}
A atividade produtora e a energia criadora do homem, movida por essa atividade engendradora de vida, o trabalho, é que deram as condições para que, ao longo das gerações, as experiências dos homens se tornassem cada vez mais ricas e a arte fosse produzida. Portanto, a arte é uma produção humana que tem suas origens na atividade reprodutiva e criadora do homem, e se constitui desde a infância, como é possível compreender a partir dos estudos de Vigotski.
\end{abstract}

Em La imaginación y el arte en la infância, Vigotski (2006) examina o carácter e o desenvolvimento da imaginação artística na criança. Para tanto, o autor inicia tratando das atividades psicológicas essencialmente humanas: a atividade reprodutora e a atividade criadora. Vigotski (2006, p. 7, tradução nossa) chama de atividade criadora "toda realização humana criadora de algo novo, a partir de determinadas construções do cérebro ou dos sentimentos que vivem ou que se manifestam sozinhos no próprio ser humano". Em sua conduta e em toda sua atividade distinguem-se dois tipos básicos de impulsos: o reprodutor e o criador (Vigotski, 2006).

A atividade criadora só foi possível graças à atividade primeira de reproduzir as experiências socialmente acumuladas pelos homens. A atividade reprodutora ou memorizadora do sujeito, como explica Vigotski (2006), está estreitamente ligada à memória e, em sua essência, possibilita ao homem reproduzir ou repetir normas de conduta já criadas e elaboradas ou ressuscitar rastros de antigas impressões. É essa capacidade reprodutora que garantiu ao homem fixar as experiências acumuladas pela humanidade, reproduzi-las e, a partir delas, criar algo novo. Nosso cérebro "constitui o órgão que conserva as experiências vividas e facilita sua re- 
produção" (Vigotski, 2006, p. 8, tradução nossa). No entanto, observa o autor que

...se sua atividade só se limitar a conservar as experiências anteriores, o homem seria um ser capaz de ajustar-se às condições estabelecidas pelo meio que o rodeia. Qualquer mudança nova, inesperada, nesse meio ambiente que não tivesse sido produzida anteriormente na experiência vivida não poderia despertar no homem a devida reação adaptadora (Vigotski, 2006, pp. 8-9, tradução nossa).

Por isso, junto a essa função que mantém as experiências anteriores, o cérebro possui outra função, que no nosso entendimento é mais complexa: a atividade que combina e cria. Exemplifica Vigotski que quando imaginamos quadros do futuro ou episódios antiquíssimos da vida do homem pré-histórico, não nos limitamos a reproduzir impressões vividas por nós mesmos, pois ainda que não tenhamos visto esse futuro ou esse passado, podemos imaginá-lo, formar uma ideia ou imagem dele. Portanto, o cérebro não se limita a ser um órgão capaz de reproduzir nossas experiências passadas, "é também um órgão combinador, criador, capaz de reelaborar e criar com elementos de experiências passadas novas formas e aproximações" (Vigotski, 2006, p. 9, tradução nossa). Na concepção de Vigotski (2006), toda atividade humana que não se limita a reproduzir fatos ou impressões vividas, mas que crie novas imagens, novas ações, pertence à função criadora ou combinadora. Nesse sentido, adverte o autor que

... se a atividade do homem se reduzisse a repetir o passado, o homem seria um ser voltado exclusivamente para o ontem e incapaz de adaptar-se ao amanhã diferente. É precisamente a atividade criadora do homem a que fez dele um ser projetado para o futuro, um ser que contribui a criar e que modifica o seu presente (Vigotski, 2006, p. 9, tradução nossa).

Nessa linha de pensamento, Lukács (2010, p.14) afirma que o homem se diferencia, quantitativa e qualitativamente, dos animais por meio do seu próprio trabalho, pois

... a função criadora do sujeito se manifesta, por conseguinte, no fato de que o homem se cria a si mesmo, se transforma ele mesmo em homem, por intermédio de seu trabalho, cujas características, possibilidades, grau de desenvolvimento etc., são, certamente, determinados pelas circunstâncias objetivas, naturais ou sociais (Lukács, 2010, p. 14).

Mas como se explica essa atividade criadora do cérebro humano? De onde surge? Como criamos? Vigotski (2006) esclarece que a psicologia chama de imaginação ou fantasia a esta atividade criadora do cérebro humano baseada na combinação. A psicologia histórico-cultural deu um sentido científico à concepção vulgar destas palavras: imaginação e fantasia. Na concepção vulgar entende-se por fantasia ou imaginação: o irreal, o que não se ajusta a rea- lidade e que, para tanto, carece de valor prático. Contrário a essa concepção, Vigotski (2006, p. 10, tradução nossa) afirma que a imaginação, como base de toda a atividade criadora do cérebro humano, baseada na combinação, é que leva o homem a modificar o presente e projetar o futuro,

.. se manifesta por igual em todos os aspectos da vida cultural possibilitando a criação artística, científica e técnica. Neste sentido, absolutamente tudo o que nos rodeia e tem sido criado pela mão do homem, todo o mundo da cultura, a diferença do mundo da natureza, todo ele é produto da imaginação e da criação humana, baseado na imaginação.

Desse modo: "Todos os objetos da vida diária, sem excluir os mais simples e habituais, vem a ser assim como fantasia cristalizada" (Vigotski, 2006, p. 10). Em todos os produtos humanos estão cristalizadas a imaginação e a capacidade criativa do homem. Vale destacar que "todo" o mundo da cultura é criado pela mão humana, ou seja, é produto humano. No decurso da atividade dos homens, as suas aptidões, os seus conhecimentos e o seu saber-fazer cristalizam-se de certa maneira nos seus produtos, sejam eles materiais, intelectuais ou ideais. Por essa razão,

... todo o progresso no aperfeiçoamento, por exemplo, dos instrumentos de trabalho pode considerar-se, deste ponto de vista, como marca de um novo grau do desenvolvimento histórico nas aptidões motoras do homem; também a complexificação da fonética das línguas encarna os progressos realizados na articulação dos sons e do ouvido verbal, os progressos das obras de arte, um desenvolvimento estético, etc. (Leontiev, 1978, pp. 283-284).

Para Vigotski (2006), a criatividade não é privativa de seres seletos, gênios, talentos, autores de grandes obras de arte, de magnos descobrimentos científicos ou de importantes melhorias tecnológicas, como concebe a concepção vulgar. Pensar dessa forma, seria como admitir que essa criação não existe na vida do homem do povo. Contrariando essa concepção vulgar, o psicólogo salienta que

... na vida que nos rodeia, todo dia têm todas as premissas necessárias para se criar e tudo o que excede os marcos de sua rotina, anexando pelo menos uma pequena partícula de novidade, tem sua origem no processo criador do ser humano (Vigotski, 2006, p. 11, tradução nossa).

Pondera o autor que se agregássemos ainda a criação coletiva que agrupa todas as contribuições insignificantes da criação individual, compreenderíamos "quão imensa é a parte de tudo o que foi criado pelo gênero humano que corresponde precisamente à criação anônima coletiva de inventores anônimos" (Vigotski, 2006, p. 11).

A partir dessa compreensão de criatividade, Vigotski (2006, p. 12, tradução nossa) afirma que os processos criadores são perceptíveis, com todo o seu vigor, desde a mais tenra idade, e que entre as questões mais importantes da 
psicologia infantil e da pedagogia figura a capacidade criadora das crianças, “... do fomento desta capacidade e sua importância para o desenvolvimento geral e do amadurecimento das crianças". Afirma o autor que, desde os primeiros anos da criança, encontram-se processos criadores que se refletem, sobretudo, em seus jogos. A mais autêntica e verdadeira criação apresenta-se na concepção de Vigotski (2006), quando um garoto cavalga em um pedaço de madeira e imagina que monta a cavalo, quando a menina brinca com sua boneca e acredita ser mãe, enfim, quando as crianças brincam de polícia e ladrão, soldados, marinheiros etc....

A função combinadora do nosso cérebro não é algo absolutamente novo em comparação à função conservadora, mas sim um dos seus resultados, ou seja, sua complexidade posterior. Portanto,

... a fantasia não está em contraposição à memória, mas se apoia nela e dispõe seus dados em novas e novas combinações. A atividade combinadora do cérebro se baseia, afinal de contas, no que o cérebro conserva, marcas e sinais das excitações precedentes, e todo o novo desta função se reduz facilmente em o cérebro, dispondo das marcas de tais excitações, combiná-las em posições distintas as que se encontravam na realidade" (Vigotski, 2006, pp. 18-19, tradução nossa).

Desse modo, o pleno desenvolvimento da atividade criadora fundamenta-se nas experiências vividas anteriormente. Portanto, Vigotski dá uma importante contribuição pedagógica ao enfatizar

... a necessidade de ampliar a experiência das crianças se queremos proporcionar-Ihes a base suficientemente sólida para sua atividade criadora. Quanto mais se veja, ouça e experimente, quanto mais aprenda e assimile, quanto mais elementos reais disponha em sua experiência, tanto mais considerável e produtiva será, para igualar a outras circunstâncias, a atividade de sua imaginação (Vigotski, 2006, p.17, tradução nossa).

Há, também, uma vinculação recíproca entre a imaginação e a emoção, pois todas as formas da representação criadora contêm em si elementos afetivos. Mas o que significa isso? Significa que "tudo o que a fantasia constrói influencia reciprocamente em nossos sentimentos, e ainda que essa construção não concorde, por si, com a realidade, todos os sentimentos que provoca são reais, efetivamente vividos pelos homens que os experimentam" (Vigotski, 2006, p. 23, tradução nossa). Essa vinculação se dá por meio da relação humana objetiva que ocorre entre o homem e o objeto, dando sentido aos objetos, em que nasce e desenvolve a riqueza da sensibilidade subjetiva humana, como o ouvido musical, o olho que descobre a beleza da forma, os sentidos espirituais como o desejo e o amor (Marx, 2010). Isso explica por que as obras de arte nos causam impressões tão profundas, pela fantasia de seus autores.
A criação literária, a criação e a arte do teatro expressam-se na idade escolar. Na tenra idade, todas as crianças passam por várias etapas de desenho, afirma Vigotski (2006), pois o desenho é o modelo de expressão típica dos pré-escolares particularmente. Nesses anos, o desenho é a ocupação preferida das crianças, no entanto, ao iniciar a idade escolar, isso desaparece por completo por não ser estimulado, alerta o autor. Na concepção de Vigotski (2006), existe um vínculo interior entre a personalidade da criança nessa idade e seu interesse por desenhos. Na criança, a concentração das forças criadoras não é casual, "mas se deve precisamente ao desenho que permite a criança desta idade expressar mais facilmente suas inquietudes" (pp. 53-54, tradução nossa). A produção literária infantil “... se encontra em tal relação com a dos adultos como os jogos estão a respeito da sua própria vida" (p. 79, tradução nossa).

Ao passar para outra fase de desenvolvimento, a criança eleva-se a uma escala superior em sua idade, afirma o psicólogo, transformando-se e mudando também as características de sua obra criadora. O desenvolvimento da linguagem falada e escrita é um exemplo de escala superior e nessa fase, cabe ao professor orientar o aluno, bem como selecionar tipos de literatura mais adequados para as crianças, a fim de conduzir suas reações artísticas. Nesse sentido, Vigotski (2006, p. 62, tradução nossa) assegura que a verdadeira educação consiste "... em despertar na criança, aquilo já possui em si, e ajudá-lo a fomentar e orientar seu desenvolvimento em uma direção determinada".

Quanto à arte do teatro, na idade escolar, é o mais próximo possível da criação literária infantil. O drama ou a representação teatral constitui o aspecto mais frequente e extenso da criação artística infantil. As crianças imitam as impressões externas que percebem no ambiente em que vivem. Com a força do seu instinto e de sua imaginação, explica Vigotski (2006, p. 85, tradução nossa), "a criança acredita nas situações e no ambiente que não lhe proporciona a vida para improvisar impulsos emocionais (heroísmo, coragem, abnegação). ... A criança interpreta em ações e em imagens vivas, tudo o que pensa e sente".

Desse modo, as imagens criadas por elementos reais, encarnam e se realizam de novo na vida real ainda que de modo condicional; o desejo de ação, de representação e de realização incorporado no mesmo processo de imaginação encontra aqui sua realização plena. A forma dramatizada tem um íntimo vínculo com os jogos. Sabe-se que "alguns pedagogos, incluem o teatro entre os métodos de ensino, até tal ponto esta eficaz forma de expressão por meio do próprio corpo responde a natureza motriz da imaginação infantil" (Vigotski, 2006, p. 91, tradução nossa).

Shuare (1990, p. 148), referindo-se aos estudos de Leontiev e de Zaporózhets, publicados na década de 1940, traz elementos que corroboram para compreender o movimento humano e o desenvolvimento da percepção estética. O movimento humano forma-se sempre na qualidade das ações, isto é, de processos dirigidos a um objetivo: "é voluntário, dirigido conscientemente ao domínio das formas de ação com os objetos ou com os instrumentos". Por isso, 
não é possível organizar-se, a partir do treinamento mecânico que pressupõe a realização de centenas de operações "puramente físicas", "periféricas". O movimento humano é resultado da formação da vida do indivíduo, de sínteses extremamente complexas.

Os estudos de Leontiev levaram-no a considerar o movimento para além do campo da "manifestação" psíquica, mas sim como "aquele que o forma, porque o movimento realiza a vinculação prática do indivíduo com o mundo circundante, vinculação que está na base do desenvolvimento dos processos psíquicos" (Shuare, 1990, p. 146).

Zaporózhets investigou a percepção estética infantil (contos, fábulas, espetáculos etc.) e chegou à conclusão de que "na formação da percepção estética se encontra os movimentos expressivos da criança, que lhe permite 'participar' dos acontecimentos que enfrentam os heróis das obras" (Shuare, 1990, p. 146). O autor reitera a indissociabilidade entre ação e pensamento, portanto, o surgimento do pensamento não é separado da ação prática.

\section{Possíveis contribuições da arte concebida por Vigotski para o desenvolvimento humano por meio do ensino da cultura corporal}

Os estudos de Vigotski contribuem para a sua compreensão de arte atrelada à constituição do gênero humano e da formação do ser social, portanto, em uma concepção histórica e dialética. De maneira específica, a Psicologia da arte tem como objeto o estudo da estrutura da obra, seja ela artística, musical ou literária; isso pode contribuir de modo significativo para a compreensão das práticas humanas, em suas dimensões social, política e econômica, em determinados períodos históricos.

A arte na concepção vigotskiana se assenta na atividade reprodutora e criadora do homem, na riqueza da experiência culturalmente acumulada e transmitida de geração em geração pelos homens e na capacidade de criar o novo a partir dela. A memória e a imaginação são funções psicológicas superiores que tornam possíveis a criação e a produção da arte. Existe uma vinculação direta entre a realidade e a imaginação e, por sua vez, uma vinculação recíproca entre imaginação e emoção. Por isso, as obras de arte desenvolvem a subjetividade humana por possibilitar experiências de sentimentos e emoções a quem se deparar com elas.

Vigotski (1999) nos ajuda a compreender que a arte surge na mais tenra idade, por meio de processos complexos que alcançam escalas cada vez mais elevadas. $O$ desenho tem um importante papel no processo de criação artística e contribui para o desenvolvimento da psique humana, assim como a linguagem escrita está para a criação literária. A especificidade da expressão por meio do corpo corresponde à natureza motriz da imaginação da criança. O espetáculo tem um papel fundamental.

De forma geral, as explicações psicológicas de Vigotski $(1999,2006)$ sobre a produção cultural e a produção artística, bem como a respeito do desenvolvimento do pro- cesso criativo, possibilitam aos professores desenvolver inúmeras possibilidades de trabalhos pedagógicos na escola, com o propósito do desenvolvimento das capacidades humanas. Quanto mais ricas forem as experiências sócio-históricas dos alunos, maiores serão as suas capacidades de se apropriar e reelaborar essas experiências de forma criadora. O professor tem um papel fundamental nesse processo, como mediador, cujo papel é orientar e direcionar os alunos em seus estudos e ações. A imaginação deve ser potencializada na infância, a fim de desenvolver a capacidade criativa e a subjetividade humana. Fundamentados nessa teoria, o trabalho pedagógico pode favorecer esse desenvolvimento na infância.

A partir dos fundamentos ontológicos é possível entender o processo de surgimento e desenvolvimento das atividades corporais até os dias de hoje. Torna-se viável, também, entender a cultura corporal na infância e as produções artísticas relacionadas às atividades corporais nesse período da vida. As crianças transformam a realidade objetiva em algo novo, por intermédio de sua capacidade imaginativa e criativa. A estrela transforma-se no elemento ginástico "roda"; a árvore da bananeira transforma-se no exercício corporal que as crianças chamam no Brasil de "plantar bananeira", que cientificamente é denominado, "parada de mãos"; o elefante, ao se equilibrar na tromba, tal qual aparece nos circos tradicionais do século passado, é objeto de imitação na qual as crianças executam um movimento chamado de "elefantinho", o qual, cientificamente, no contexto da prática da Ginástica Artística, é chamado de "parada de três apoios" (Palharini, 2007). A realidade objetiva, portanto, torna-se material para o conteúdo e estilo artístico, apreendidos da realidade objetiva e trabalhados a partir dela (Barroco \& Superti, 2014).

O elemento corporal artístico, como um espetáculo de dança ou uma série de ginástica artística ou rítmica, ou uma patinação artística, é produção artística e, portanto, uma obra cultural, porque emprega toda a cultura corporal produzida historicamente, pelos homens aliada à capacidade criativa e à capacidade expressiva humana. Desse modo, a produção artística expressa emoções e sentimentos de quem apresenta e representa e, ao mesmo tempo, provoca em quem assisti, um deleite pela sua beleza e plasticidade (Leontiev, 1978; Vigotski, 2006; Lukács, 2010).

Os estudos sobre a Psicologia da Arte contribuem para a análise da estrutura das obras além de permitir avançar na análise de peças artísticas, musicais e literárias. Um exemplo disso é o trabalho desenvolvido por Borges (2015), no qual analisou a obra "Jogos Infantis" de Pieter Bruegel (1525-1569), a partir da forma e conteúdo em relação à percepção estética, tomando como fundamento os estudos de Vigotski, entre outros autores; essa autora entende que as imagens contidas na obra "contribuem para a compreensão do papel histórico e ativo do sujeito e também dos períodos históricos da história da humanidade e as perspectivas de seu desenvolvimento" (Borges, 2015, p. 9). A estudiosa identificou inúmeros jogos e brincadeiras da cultura corporal presentes na obra analisada, os quais reforçam tal entendimento. 
Particularmente para o ensino da educação física, são muitas as contribuições da teoria de Vigotski (1999, 2006) sobre arte. Ensinar os elementos da cultura corporal com o intuito de impulsionar o desenvolvimento da capacidade reprodutora e criadora da criança é uma das principais contribuições. Os estudos de Vigotski e de seus colaboradores e continuadores, corroboram a necessidade de se desenvolver, por meio da educação física, os aspectos motores juntamente com a criatividade, a criação de novos movimentos na dança, na ginástica, nos jogos, a partir da vivência que a criança tem. Por fim, a concepção vigotskiana de arte permite promover o desenvolvimento da capacidade expressiva nas crianças, como resposta a imaginação da criança.

\section{Conclusão}

Os estudos das obras de Vigotski acerca da arte e a arte na infância possibilitam avançar para a compreensão sócio-histórica do homem e da produção da arte, bem como das origens da criação na psique humana. Os estudos sobre ensino e aprendizagem no Brasil estão bastante avançados, entretanto, os estudos sobre a arte na concepção histórico-cultural de Vigotski estão em estágio inicial na área da educação, da psicologia e, particularmente, da educação física; o estudo da perspectiva de arte de Vigotski apresenta-se como um campo de investigação fecundo, dada a riqueza da produção desse autor e as suas contribuições para as áreas mencionadas, além da possibilidade de avançar para além das perspectivas dominantes.

Os estudos sobre a Psicologia da Arte contribuem para a análise da estrutura das obras e permitem avançar para analisar como as peças artísticas, musicais e literárias contêm elementos para a compreensão das práticas humanas em seus diversos períodos, constituindo-se de grande importância para o desenvolvimento da percepção estética e da subjetividade humana.

Subsidiados nas contribuições desse psicólogo russo, professores, educadores e pais devem oferecer meios, direcionamentos e mediações para que as crianças desenvolvam a sua capacidade reprodutora, combinadora e criadora como intuito de promover o desenvolvimento humano em sua totalidade.

No âmbito específico das ações pedagógicas em educação física, especialmente, com crianças em processo de escolarização, considera-se, neste estudo, que os estudos de Vigotski sobre a arte e desenvolvimento na infância podem contribuir sobremaneira para avanços nos processos de compreensão e ensino da cultura corporal.

\section{Referências}

Almeida, E.M. (2015). As pesquisas sobre ginástica no Brasil e as apropriações da Teoria Histórico-Cultural. Monografia, Universidade Estadual de Maringá, Maringá-PR.
Barroco, S.M.S. \& Superti, T. (2014). Vygotsky e o estudo da psicologia da arte: contribuições para o desenvolvimento humano. Psicologia e Sociedade, 26 (1). 22-31.

Borges, J.F. (2015). Jogos Infantis: aspectos históricos e estéticos da obra de Bruegel. Monografia, Universidade Estadual de Maringá, Maringá-PR.

Jácome, M.Q.D. (2006). As apropriações da Teoria de Vigotski em Livros de Psicologia voltados para a formação de professores, Dissertação de Mestrado.Universidade de Brasília. Brasília-DF.

Leontiev, A. (1978). O desenvolvimento do psiquismo. Lisboa: Livros Horizonte.

Lukács, G. (2010). Introdução aos escritos estéticos de Marx e Engels. Em K. Marx \& F. Engels, Cultura, arte e literatura: textos escolhidos (pp. 11-38). São Paulo: Expressão Popular.

Marroni, P. C. T. (2003). Circo: um Universo Mágico de Conhecimento e Arte. Monografia, Universidade Estadual de Maringá, Maringá$\mathrm{PR}$.

Marx, K. \& Engels, F. (2010). Cultura, arte e literatura. Textos escolhidos. São Paulo: Editora Expressão Popular.

Lei $n^{\circ}$. 9.394, de 20 de dezembro de 1996 (1996, 20 de dezembro). Lei de Diretrizes e Bases da Educação Nacional. Brasília: Ministério da Educação e Cultura. Recuperado: 15 ago. 2014. Disponível: http://bd.camara.gov.br/bd/bitstream/handle/bdcamara/ 2762/ Idb_5ed.pdf.

Palharini, A.(2007). O conhecimento gímnico na cultura infantil. Monografia, Universidade Estadual de Maringá, Maringá-PR.

Piedade, V.V. (2004). A construção do corpo expressivo. Uma análise a partir das obras de Constantin Stanislavski e Bertolt Brecht. Monografia, Universidade Estadual de Maringá, Maringá-PR.

Sarmento, D.F. (2006). A Teoria Histórico-Cultural de L. S. Vygotsky. Tese de Doutorado, Universidade Federal do Rio Grande do Sul, Porto Alegre-RS.

Shuare, M. (1990). La psicología soviética tal como yo la veo. Moscú:Editorial Progreso.

Silva. F.G. \& Davis, C.(2004). Conceitos de Vigotski no Brasil. Produção divulgada nos cadernos de pesquisa. Cadernos de Pesquisa, 34 (123). 633-661.

Soares, C.L. (2005). Imagens da educação no corpo. Estudo a partir da ginástica francesa no século XIX (3a. ed.). Campinas: Editora Autores Associados.

Soares, C.L., Taffarel, C., Varjal, E., Castellani Filho, L., Escobar, M.O., \& Bracht, V. (1992). Metodologia do ensino de Educação Física. São Paulo: Editora Cortez. 
Vigotski, L.S. (1999). A psicologia da arte. São Paulo: Editora Martins Fontes.
Vigotski, L.S. (2006). La imaginación y el arte en la infância. Ensayo psicológico. Madrid: Ediciones Akal.

Recebido em: 01 de setembro de 2016

Aprovado em: 21 de novembro de 2016

\section{Sobre as autoras}

Telma Adriana Pacifico Martineli (telmamartineli@hotmail.com)

Doutora em Educação. Docente do Programa de Pós-Graduação em Educação. Universidade Estadual de Maringá, Maringá-PR.

Eliane Maria Almeida (elianemarialmeida@hotmail.com)

Graduação em Educação Física. Atua na Prefeitura Municipal de Paiçandu, Paiçandu - PR.

Concepção vigotskiana de arte * Telma Adriana Pacifico Martineli \& Eliane Maria Almeida 